\title{
Industry-based development of effective new seabird mitigation devices in the southern Australian trawl fisheries
}

\author{
Matt Koopman ${ }^{1}$, Simon Boag ${ }^{2, *}$, Geoffrey N. Tuck ${ }^{3}$, Russell Hudson ${ }^{1}$, Ian Knuckey ${ }^{1}$, \\ Rachael Alderman ${ }^{4}$
}

\author{
${ }^{1}$ Fishwell Consulting Pty Ltd, 27A Hesse Street, Queenscliff, VIC 3225, Australia \\ ${ }^{2}$ South East Trawl Fishing Industry Association (SETFIA), PO Box 1125, Lakes Entrance, VIC 3909, Australia \\ ${ }^{3}$ CSIRO Oceans and Atmosphere, Castray Esplanade, Hobart, TAS 7000, Australia \\ ${ }^{4}$ Department of Primary Industries, Parks, Water and Environment, 134 Macquarie Street, Hobart, TAS 7000, Australia
}

\begin{abstract}
Incidental mortality of seabirds caused by interactions with the warp wires of trawl vessels in Australia's Commonwealth-managed Southern and Eastern Scalefish and Shark Fishery has been reported by on-board observers. Seabird mortality as a result of fishery interactions is an issue of global conservation concern. This paper describes an industry-led study that developed and tested the effectiveness of 2 experimental mitigation devices for trawl vessels: a baffler and a water sprayer. These were tested against a control which was previously the only prescribed device (a warp deflector called a pinkie). Seabird interactions were observed during 69 shots comparing the sprayer against the control, and 55 shots comparing the baffler against the control. The seabird mitigation device employed alternated between the trial device (either the water sprayer or baffler) and the control device. Both experimental mitigation devices showed significant reductions in heavy interaction rates (interactions per shot) compared with the pinkie (83.7 and 58.9\%). On stern trawlers, both new devices are deployed at the start of fishing and retrieved at the end of fishing operations, whereas pinkies need to be deployed and retrieved for each shot. This results in time savings and reduced risks to crew. Based on the findings from this study, the Australian Fisheries Management Authority now allows vessels to meet seabird bycatch mitigation requirements through use of either new device. The outcomes of this research and subsequent uptake of the new mitigation devices will greatly contribute to the reduction of incidental fishing mortality in Australian, and potentially other trawl fisheries.
\end{abstract}

KEY WORDS: Mitigation measures - Seabirds - Commercial fishery · Fishery interactions · Conservation · Australia $\cdot$ Fishery bycatch

\section{INTRODUCTION}

Seabirds are considered the most threatened of all bird groups (Croxall et al. 2012) and fishing-related seabird mortalities are considered the most pervasive threat to seabird conservation status (Gales 1998, Phillips et al. 2010, Alderman et al. 2011, Croxall et al. 2012, Favero \& Seco Pon 2014). Attention originally focused on seabird interactions with

${ }^{*}$ Corresponding author: simonboag@setfia.org.au longline fisheries (Brothers 1991, Weimerskirch et al. 1997, Nel et al. 2002, Tuck et al. 2003, 2011); however, trawl fisheries are also known to cause substantial seabird mortalities (Sullivan et al. 2006b, Moore \& Zydelis 2008, Watkins et al. 2008, Favero et al. 2011, González-Zevallos et al. 2011). Seabirds have wide-ranging foraging distributions, are longlived, with low fecundity and a late age-at-maturity (Warham 1990), which are all characteristics that

(C) The authors 2018. Open Access under Creative Commons by Attribution Licence. Use, distribution and reproduction are unrestricted. Authors and original publication must be credited. 
make their populations vulnerable to any additional mortality.

Seabirds are attracted to trawl vessels to feed on fish bycatch or offal that is discarded (Williams \& Capdeville 1996, Crawford 2007). Aggressive competition for this food off the stern of the vessel places seabirds in the area where the warp cables (the 2 steel cables used to tow trawl nets) enter the ocean, and at increased risk of harmful interactions. These can include net capture (Bull 2009, Pierre et al. 2010), collisions with the vessel (Ramm 2012, Australian Fisheries Management Authority [AFMA] unpubl. data), and collisions with the third wire or net sonde (Weimerskirch et al. 2000) or, more commonly, with the warps (Moore \& Zydelis 2008, Watkins et al. 2008, Abraham 2010, Maree et al. 2014). Most interactions with seabirds in trawl fisheries in southeast Australia occurred from collisions with the warp cables (warp strike); collisions with vessels and captures in Australian trawl nets are extremely rare (M. Gerner pers. comm.).

A large number of mitigation measures have been trialled internationally or used to reduce cable strikes. These measures generally involve physical deterrents of one form or another, such as bird scaring lines (otherwise known as BSLs, tori lines or streamer lines), bird scarers and bafflers, warp booms (Melvin et al. 2011) and warp deflectors (Melvin et al. 2011, González-Zevallos et al. 2007). In addition to the use of mechanical mitigation measures, reducing the incentive for seabirds to approach the stern of the vessel by managing the discharge of offal and bycatch through fish mealing, mincing, batching and full retention can be effective at reducing interactions (Pierre et al. 2012a).

High densities of seabirds overlap with fishing effort in Australian waters (Favero \& Seco Pon 2014). The Southern and Eastern Scalefish and Shark Fishery (SESSF) is a multi-gear fishery that includes nontrawl and trawl sectors, including the Commonwealth Trawl Sector (CTS). It is the largest Commonwealthmanaged fishery by tonnage, and many interactions between SESSF fishing vessels and seabirds have been reported, both by long-line vessels (Lewison et al. 2014) and demersal and midwater (otter) trawlers (Phillips et al. 2010). By extrapolating observer data that monitored $3.6 \%$ of the total effort in the fishery, Phillips et al. (2010) estimated that from the 23774 CTS shots (trawl sets) undertaken in 2006, there were interactions with 250 black-browed albatross Thalassarche melanophris and 861 with shy albatross T. cauta. Fishery impacts on shy albatross have been particularly highlighted through popula- tion modelling by Thomson et al. (2015), who concluded that mortalities from interaction with trawl fisheries may need to be reduced by $50 \%$, in order to offset the impacts on chick survival of the predicted increases in maximum temperatures during the chick rearing season due to climate change.

In response to a government review of threats and research priorities for albatrosses that called for reducing bycatch through greater implementation and development of best-practice mitigation measures in trawl fleets (DSEWPC 2011), the AFMA, with the support of the South East Trawl Fishing Industry Association (SETFIA), implemented Seabird Management Plans (SMPs) for every CTS otter trawl vessel, effective from 31 October 2011. SMPs contained a range of measures to reduce interactions, including the use of a warp deflector (a buoy known as a 'pinkie' that is clipped to the warp and suspended on the sea surface; see Fig. 4 below) while the gear is deployed during daylight hours. Sea trials in the CTS have shown that this device reduced the number of 'heavy' interactions by $75 \%$ (Pierre et al. 2014). Prior to completion of the current study, the pinkie was the only seabird mitigation device permitted in seabird management plans. While compliance with SMPs is generally high, there has been some non-compliance reported (for example, see ANAO 2013).

A wide variety of fishing gear and deck equipment is used by otter trawl vessels operating in the CTS. Whilst the use of a particular mitigation device may be straightforward on one vessel, its use on a different vessel may pose complications, including safety hazards. Tuck et al. (2013) documented that during deployment and retrieval of pinkies, fishing crews can be exposed to elevated risk of injury. One example of this is an increased risk of injury or man-overboard on vessels where the blocks are positioned outside of the gunnels, requiring fishing crew to reach over the side of the vessel to clip and unclip the pinkie to the warp. Further, anecdotal information from observers and fishermen suggests that these risks are further elevated during bad weather. Ideally, a range of effective mitigation devices or flexibility of design within a single device should be available, allowing the skipper to choose which is most suitable for the particular vessel.

Fishers can provide valuable insights and solutions to reduce bycatch (Boyd 2014). In the South African trawl fishery, the design of current bird-scaring line regulations was developed through engagement with fishing crew and trials to optimise safety, operational practicality, and mitigation performance (Wanless \& Maree 2014). SETFIA recognised this in their 
strategic plan, and in partnership with the Great Australian Bight Fishing Industry Association (GABIA), SETFIA initiated the Australian Government-funded project whose results are described in this paper. The project aimed to develop one or more mitigation devices (in addition to pinkies) that are effective at reducing seabird interactions, do not elevate health and safety risks and could be included within SMPs.

This study describes 2 mitigation devices developed and/or adapted by SETFIA members that were selected for sea trials during commercial fishing operations, and the results of these trials. The aim of the sea trials was to compare the interaction rates of each device to the pinkies currently prescribed by seabird management plans, and examine the factors that impact the effectiveness of the seabird mitigation devices.

\section{MATERIALS AND METHODS}

\section{Trial design}

Sea trials were undertaken off southeast Australia (Fig. 1) from November 2014 to October 2015. Trials of the baffler were undertaken on 'Vessel A', which is a 29 m, 135 t stern trawler based out of Eden, NSW. Trials of the Sprayer were undertaken on 'Vessel B', which is a $20 \mathrm{~m}, 100 \mathrm{t}$ stern trawler based out of Lakes Entrance, Victoria. All trials were conducted during normal commercial fishing conditions, and the pinkie buoy was used as the control on both vessels.

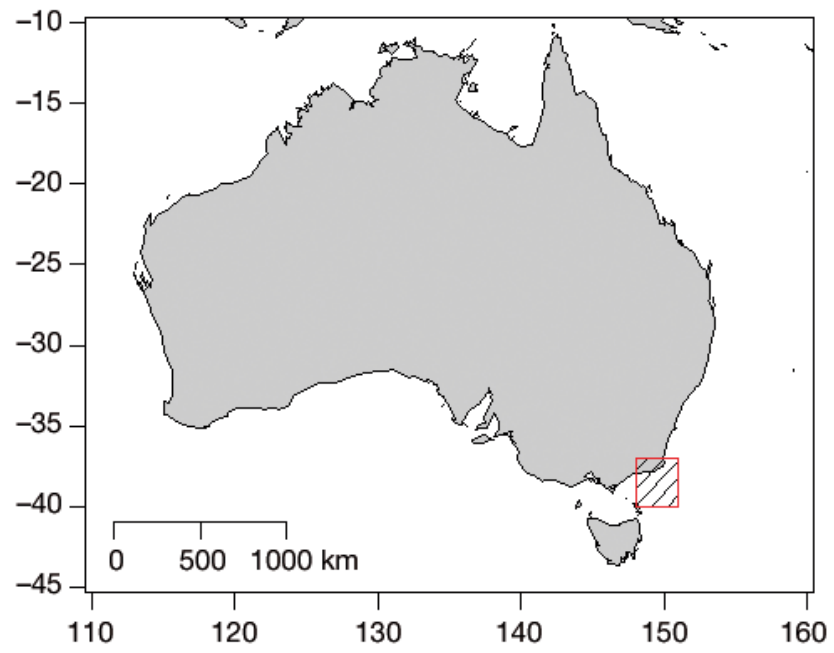

Fig. 1. Area of southeast Australia where sea trials took place to test the effectiveness of experimental seabird interaction mitigation devices, in comparison with the pinkie, which was previously the only prescribed device
To account for differences in the performance of the treatment at different times of day, and under varying environmental and operational conditions, deployment of either the control or the alternative device during the first shot was randomly selected by the observer, and then alternated throughout the day. The first device deployed was alternated on each successive day for the duration of the trip.

\section{Design of mitigation devices}

$$
\text { Baffler (Vessel A) }
$$

Bafflers are generally comprised of two booms that extend out from each stern quarter of a vessel, two extending out from the sides and the other two backwards from the stern (Bull 2009, ACAP 2016). A number of 'droppers' (lines of various types) are suspended from the booms to create a curtain near where the warps enter the water (Bull 2009, Sullivan et al. 2006a), effectively blocking the seabirds from the region of greatest likely interaction.

The baffler used in this trial was designed by the operators of Vessel A after the study tour of New Zealand fisheries, and then tested and modified early during the trials with the addition of curtains to prevent seabirds approaching the warps from the side. It is assumed that changes made improved the effectiveness of the baffler at mitigating interactions, and this is supported by the fact that no heavy interactions were observed when using that mitigation device after changes had been made. Thus, interaction rates reported for the baffler would likely be even lower if the final version of the baffler was used from the beginning. For this reason, the data for the entire trial period were combined. The final baffler design comprised 2 booms extending laterally approximately $5 \mathrm{~m}$ from the port and starboard stern quarters, with a 'back-bone' line extending to the end of each boom (Fig. 2). Four $6 \mathrm{~m}$ long 'droppers' were suspended from the back-bone line to the surface of the water. Droppers were constructed of nylon rope covered in orange-coloured $25 \mathrm{~mm}$ PVC conduit cut into $100 \mathrm{~mm}$ lengths to provide flexibility. An outside curtain that was $18 \mathrm{~m}$ long with 6 droppers decreasing in length astern $(5,3,2.5,1.5,1$ and $0.5 \mathrm{~m})$ was suspended from the back-bone line to the surface of the water. A $600 \mathrm{~mm}$ pinkie buoy was attached to the end of the outside curtain to provide drag and keep the backbone line taut. During deployment of the control device, bafflers were retrieved, and the streamers were removed from the booms. 

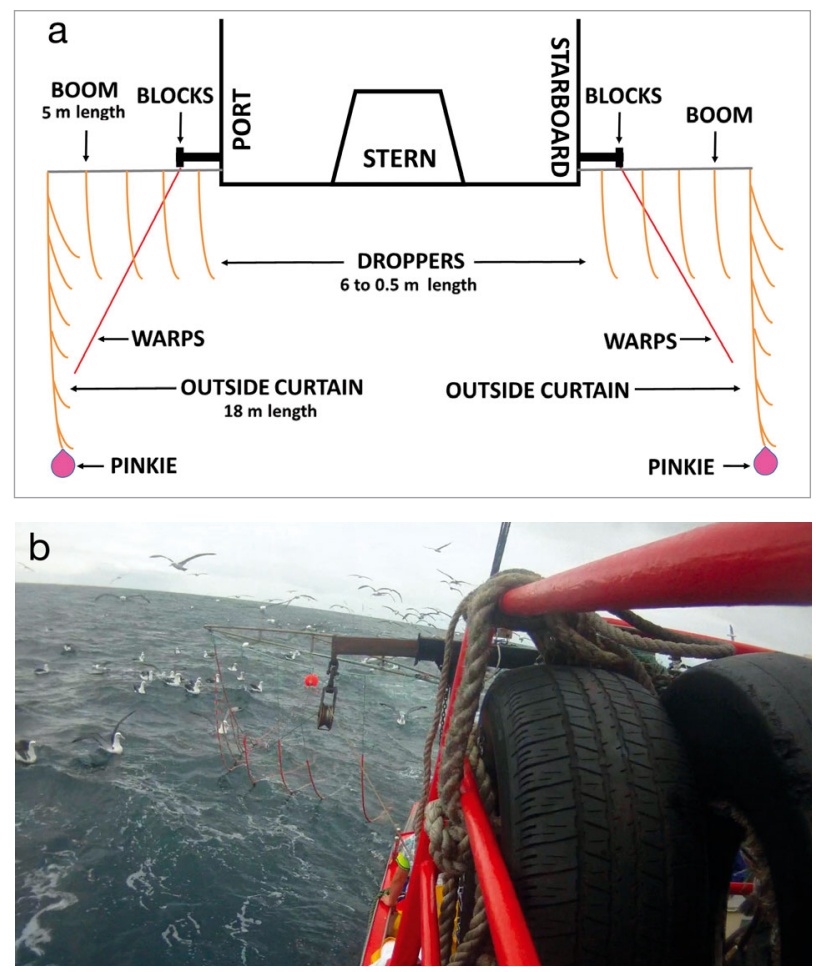

Fig. 2. (a) Diagrammatic representation of the 'baffler' seabird bycatch mitigation method. (b) The baffler in use during trials off southeast Australia

\section{Sprayer (Vessel B)}

Like bafflers, the sprayer creates a barrier around the warp-water interface but uses jets of water instead of droppers. The sprayer underwent significant testing and redesign before the trials started. The final sprayer design comprised two $4 \mathrm{~m}$ booms extending beyond the stern over the warps, each with two $4 \mathrm{~m}$ arms separated by a $2 \mathrm{~m}$ gap (Fig. 3). Sea water is pumped into the arms, and out through nozzles that can be adjusted to obtain the desired spray effect of a 'curtain' of water around each warp of approximately $6 \mathrm{~m}$ long $\times 4 \mathrm{~m}$ wide. During deployment of the control device, the sprayer was raised to a vertical position so as not to effect the mitigation rates of the pinkies.

Pinkie

The control device for both the sprayer and the baffler was the pinkie buoy described in Pierre et al. (2014). In line with AFMA's SMPs, the pinkies were $600 \mathrm{~mm}$ in diameter and $820 \mathrm{~mm}$ in height from the bottom of the buoy to the centre of the top eye hole. After setting, the pinkies were clipped onto the warp,
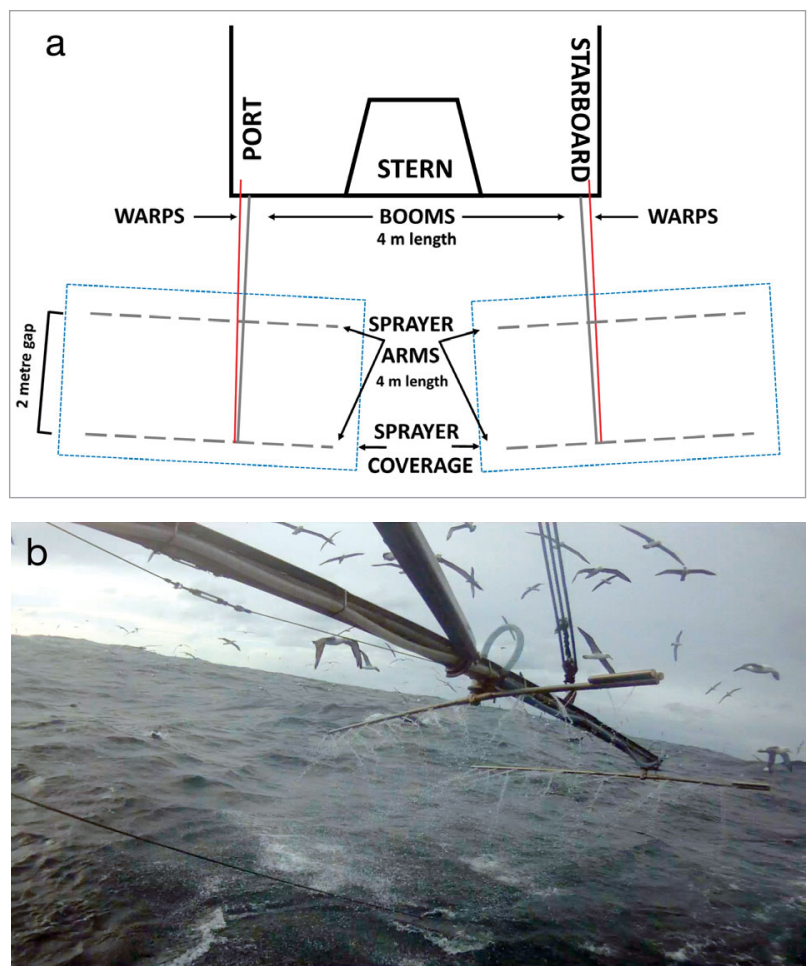

Fig. 3. (a) Diagrammatic representation of the water sprayer seabird bycatch mitigation method. (b) The water sprayer in use during trials off southeast Australia

and lowered via a rope so that the bottom of the pinkie was no more than $400 \mathrm{~mm}$ from the sea surface (Fig. 4).

\section{Data collection}

Data collection was based on the methods of Pierre et al. (2014) to record seabird interactions, seabird abundance and behaviour, and other information to

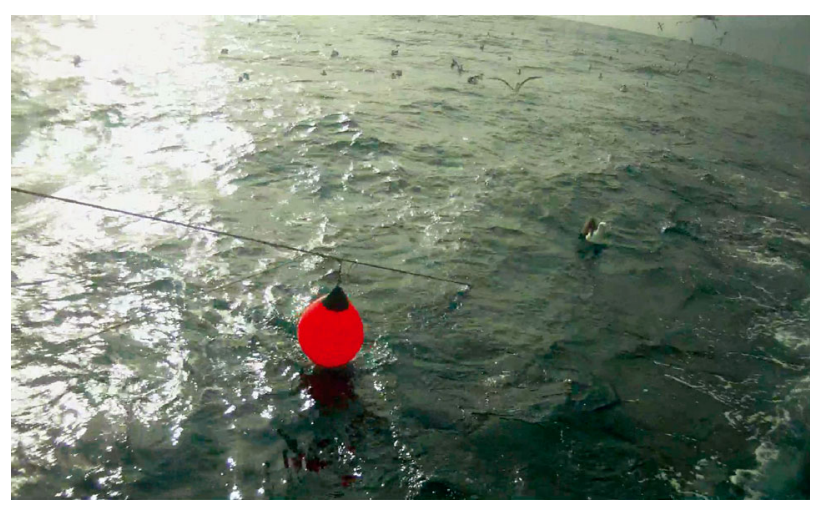

Fig. 4. The $600 \mathrm{~mm}$ diameter pinkie, which was previously the only prescribed device to mitigate seabird interactions with trawl vessels, used as the control in trials to test the effectiveness of 2 experimental mitigation devices 
enable comparison of interactions between devices, and the effect of other factors on interaction rates. Operational (time and date, location, depth) and environmental variables (wind direction and speed, sea height, swell height and direction, cloud cover in octares, precipitation, barometric pressure, moon phase) were recorded for each shot as well as total catch, total discarded weight, weight of main retained and discarded species and weight of offal discharged (see Table 3 below). Observations and interviews with crew members were used to make a qualitative assessment of comparative safety and ease of use of each device.

The presence of seabirds is an obvious prerequisite for seabird mortalities, and it was hypothesised that interaction rates would be positively correlated to abundance of seabirds. Abundance estimates were made from the stern of the vessel in an area covering a $180^{\circ}$ arc, out to a distance of $250 \mathrm{~m}$ from the vessel. Seabird numbers were accurately counted for 1 to 10 birds, and for greater numbers estimated using the procedures shown in Table 1. Five different stages of trawling were considered during abundance estimates for each shot: (1) before deploying the gear; (2) after either the gear is deployed on the first shot (no prior discharge or processing) or immediately after processing on every subsequent shot; (3) as the gear is being hauled; (4) after the catch is released from the net onto the deck; and (5) during bycatch offal discharge.

Seabirds were identified to species level where possible, however shy albatross Thalassarche cauta and white-capped albatross T. steadi are phenotypically similar, and their distributions overlap (Baker et al. 2007). Therefore, no effort was made to differentiate them, and both species are combined into a single group referred to as 'shy-type albatross'. Similarly, observers were sometimes unable to confidently distinguish between the 2 closely related species, Campbell and black-browed alba-

Table 1. Procedures for assessing abundances of seabirds at sea (based on Pierre et al. 2014)

\begin{tabular}{|ll|}
\hline Number range & Procedure \\
\hline $1-10$ & Count accurately \\
$11-30$ & Count accurately or estimate by $5 \mathrm{~s}$ \\
$31-100$ & Estimate by 10s \\
$101-200$ & Estimate by 25s \\
$201-500$ & Estimate by 50s \\
$501-1000$ & Estimate by 100s \\
$1000-2000$ & Estimate by 200s \\
$2000+$ & Estimate by 500s \\
\hline
\end{tabular}

tross, and so here we combine both species ( $T$. melanophris and T. impavida) into the single 'blackbrowed' group.

The seabird interaction observation period commenced during catch processing and discarding, and focused on the starboard warp. This period continued until all processing and discarding was finished and the deck was washed down. The entire observation time was divided into $5 \mathrm{~min}$ observation periods. Within each 5 min period, any seabird interactions were categorised based on species, contact code (Table 2), and contact point (the warp or the mitigation device) on which the interaction occurred. Observations were always made from the starboard side of the vessel.

Observations were only recorded between the times of first light (30 min before sunrise) and dusk (30 min after sunset) and when bycatch and offal discard processing was undertaken. This decision was based on the extremely low number of interactions observed during the night by Pierre et al. (2014). Net interactions were not recorded because Pierre et al. (2014) reported that none of the interactions with the net observed during their study were 'considered likely to cause injury'. There is no evidence that net interactions are and issue in the CTS.

Table 2. Contact codes for rating interactions between seabirds and warps or mitigation devices on trawl vessels (based on Pierre et al. 2014)

\begin{tabular}{|c|c|}
\hline Code & Definition \\
\hline $1 \mathrm{~W}$ & $\begin{array}{l}\text { Bird on water, very light contact, does not } \\
\text { deviate from course }\end{array}$ \\
\hline $2 \mathrm{~W}$ & $\begin{array}{l}\text { Bird on water, light contact, deviates from course } \\
\text { (causes no stress or injury) }\end{array}$ \\
\hline $3 W$ & $\begin{array}{l}\text { Bird on water, heavy contact with warp wire or } \\
\text { mitigation device, dragged under and resurfaces } \\
\text { (causes stress or possible injury) }\end{array}$ \\
\hline $4 \mathrm{~W}$ & $\begin{array}{l}\text { Bird on water, heavy contact with warp wire or } \\
\text { mitigation device, dragged under, fate unknown. } \\
\text { Environmental conditions and/or seabird activity } \\
\text { preclude observer from determining whether } \\
\text { bird remained on warp wire or resurfaced. }\end{array}$ \\
\hline $5 \mathrm{~W}$ & $\begin{array}{l}\text { Bird on water, heavy contact with warp wire or } \\
\text { mitigation device, dragged under, and remains } \\
\text { on wire. Environmental conditions and/or } \\
\text { seabird activity enable observer to determine } \\
\text { that bird remained on warp wire and did not } \\
\text { resurface. }\end{array}$ \\
\hline $6 \mathrm{~F}$ & $\begin{array}{l}\text { Bird flying, light contact with warp wire or } \\
\text { mitigation device, does not deviate from course }\end{array}$ \\
\hline $7 F$ & $\begin{array}{l}\text { Bird flying, heavy contact with warp wire or } \\
\text { mitigation device, deviates from course }\end{array}$ \\
\hline
\end{tabular}




\section{Data analysis}

The main metric used in the evaluation of the efficacy of the trial devices compared to the control in our study was the number of heavy interactions, which are considered a proxy for seabird mortalities (Sullivan et al. 2006a,b). Light interactions were also recorded. In the present study, we define heavy interactions as those within categories $3 \mathrm{~W}, 4 \mathrm{~W}$ and $5 \mathrm{~W}$ of Table 2, while all remaining categories were considered 'light interactions'. To be consistent with Pierre et al. (2014), interaction category $7 \mathrm{~F}$ was not grouped with heavy interactions. In addition, category $7 \mathrm{~F}$ differs from other heavy interactions because it does not involve seabirds being dragged under the water. In accordance with AFMA's definition of a protected species interaction ('any physical contact a person, boat or fishing gear has with a protected species that causes the animal stress, injury or death', www.afma.gov.au/portfolio-item/ seabirds/), interactions with the warps and the mitigation device itself were combined. It was important to combine interactions with the mitigation devices with those on the warps because both trial devices have large booms, which could potentially cancel out benefits from reductions in warp strike. Species were combined to simplify analyses. Multiple observations within a shot were also combined as they cannot be considered statistically independent.

The data comprised a relatively high number of zero observations, and a diminishing frequency of observations with increasing interaction rates. Consequently, the variances of the interaction rates were much larger than their means. A range of methods for modelling over-dispersed data were examined using goodness-of-fit with a chisquare test based on the residual deviance and degrees of freedom. This suggested that a negative binomial model was the most appropriate. The generalised linear model (GLM) framework was used to test for significant differences between treat- ments. Analyses were undertaken using the glm.nb function in the MASS package (Venables \& Ripley 2002) using the statistical package $R$ version 3.1.1 ( $R$ Development Core Team 2014). The influence of a select number of covariates (see Table 3) was examined by the step function with the direction set to 'both' (the stepwise search is done in both directions). The step function performs a stepwise model selection by using the Akaike information criterion (AIC).

Bias-adjusted mean interaction rates and $95 \%$ confidence intervals were calculated by bootstrapping with replacement using the boot package (Canty \& Ripley 2014) in the statistical package R. We used 10000 bootstrap replicates (Sullivan et al. 2006a) with replacement.
Table 3. (a) Categorical and (b) continuous explanatory variables included in the full model for trials of the baffler (fitted on Vessel A) and water sprayer (Vessel B) in comparison with the only seabird interaction mitigation device previously prescribed, a warp deflector known as a 'pinkie' ('control'). For each variable, the table shows the corresponding units or fixed values (for continuous and categorical variables, respectively) and ranges of values observed (for continuous variables)

(a) Categorical variables

Variable Fixed values

Depth category

Moon phase

Wind direction

Direction of barometric

pressure

(b) Continuous variables

\begin{tabular}{|c|c|c|c|c|c|}
\hline \multicolumn{6}{|l|}{ (b) Continuous variables } \\
\hline \multirow[t]{3}{*}{ Variable } & \multirow[t]{3}{*}{ Unit } & \multicolumn{4}{|c|}{ - Range observed } \\
\hline & & \multicolumn{2}{|c|}{ — Vessel A — } & \multicolumn{2}{|c|}{ _ Vessel B } \\
\hline & & Baffler & Control & Sprayer & Control \\
\hline Average depth fished & $\mathrm{m}$ & $55-505$ & $55-510$ & $110-500$ & $70-480$ \\
\hline Swell height & $\mathrm{m}$ & $0.4-2$ & $0.5-1.5$ & $0-2.5$ & $0-3$ \\
\hline Wind speed & knots & $3-20$ & $5-20$ & $0-25$ & $0-20$ \\
\hline \multicolumn{6}{|l|}{ Discarded fish } \\
\hline Barracouta & & $0-80$ & $0-1200$ & $0-350$ & $0-400$ \\
\hline Blacktip cucumberfish & & $0-70$ & $0-200$ & $0-200$ & $0-200$ \\
\hline Blue grenadier & & $0-100$ & $0-4000$ & $0-2000$ & $0-1500$ \\
\hline Cocky gurnard & & $0-150$ & $0-300$ & $0-400$ & $0-400$ \\
\hline Total discarded weight & $\mathrm{kg}$ & $0-364$ & $0-500$ & $0-460$ & $0-397$ \\
\hline \multicolumn{6}{|l|}{ Retained fish } \\
\hline Blue grenadier & & $0-5000$ & $0-1800$ & $0-600$ & $0-3000$ \\
\hline Frostfish & & $0-1080$ & $0-1800$ & $0-1290$ & $0-1200$ \\
\hline Gould squid & & $0-660$ & $0-720$ & $0-2400$ & $0-2520$ \\
\hline Mirror dory & & $0-350$ & $0-100$ & $0-70$ & $0-180$ \\
\hline Pink ling & & $0-400$ & $0-300$ & $0-210$ & $0-180$ \\
\hline Tiger flathead & & $0-210$ & $0-150$ & $0-390$ & $0-330$ \\
\hline Total retained weight & $\mathrm{kg}$ & $0-300$ & $0-500$ & $0-420$ & $0-300$ \\
\hline Offal discharged & $\mathrm{kg}$ & & & & \\
\hline Blue grenadier & & $0-800$ & $0-1000$ & $0-480$ & $0-360$ \\
\hline Total offal discharged & $\mathrm{kg}$ & $64-1488$ & $116-2618$ & $151-3170$ & $79-4098$ \\
\hline
\end{tabular}

Shelf / slope

Eight principal and intermediate moon phases 16 point compass bearing

Rising / steady / falling 


\section{RESULTS}

\section{Seabird interactions}

Results demonstrate that both trial devices were more effective at mitigating seabird interactions than the pinkie. On Vessel A, the heavy interaction rate when using the baffler ( 0.1 interactions per shot) was significantly less $(\mathrm{p}<$ $0.05)$ than when the pinkies were deployed (0.8 interactions per shot). Conversely, the light interaction rate was higher for the baffler (8.7 interactions per shot) than the pinkies (6.1 interactions per shot) (Fig. 5, Tables 4 \& 5). On Vessel $B$, the heavy interaction rate when using the sprayer (2.5 interactions per shot) was significantly less $(p=0.010)$ compared to the pinkies (6.1 interactions per shot), while there was a mean of 15.4 light interactions per shot when the sprayer was deployed compared to 35.7 interactions per shot for the pinkies (Fig. 5, Tables 4 \& 6). This represents a decrease in heavy interactions of

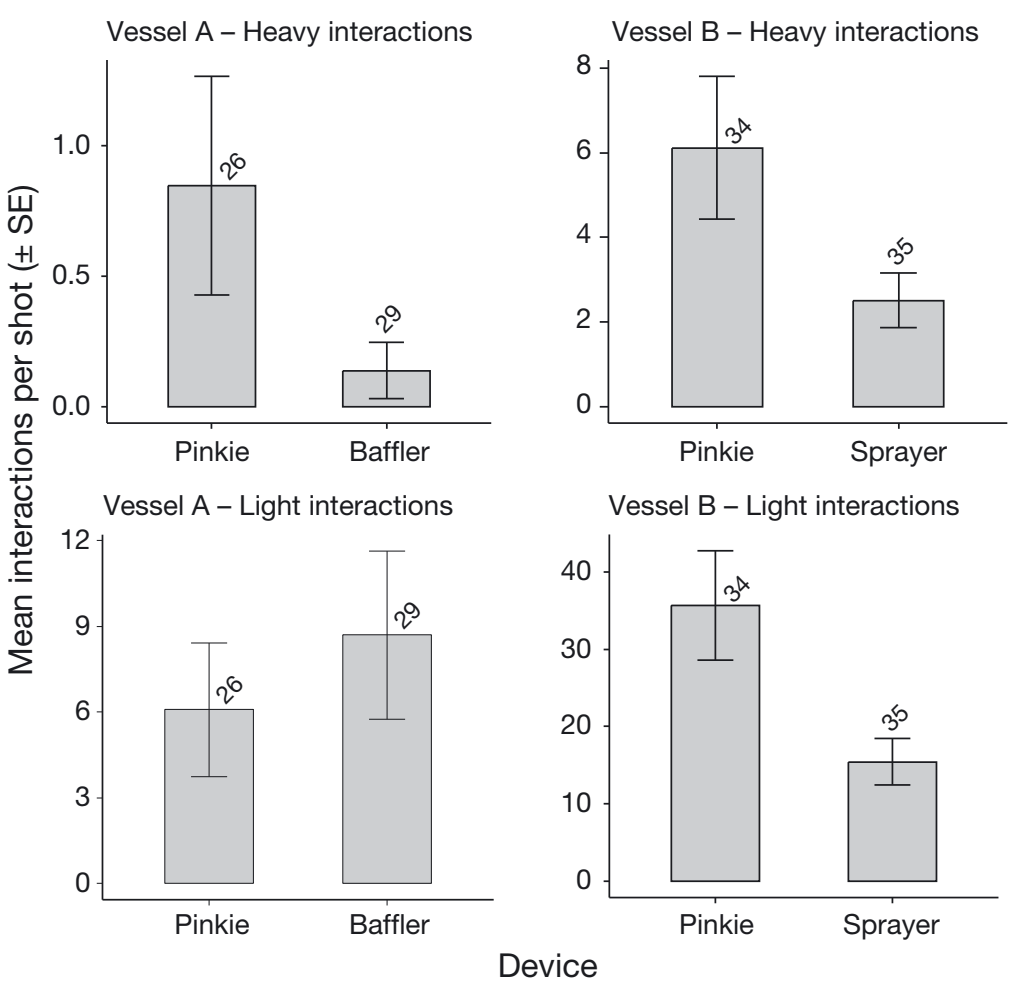

Fig. 5. Mean $( \pm \mathrm{SE})$ 'heavy' and 'light' interaction rates observed during trials of the baffler (fitted on Vessel A, left panels) and water sprayer (Vessel B, right panels) in comparison with the only seabird interaction mitigation device previously prescribed, the pinkie (control). Figures above the bars show number of shots observed
$83.7 \%$ by the baffler, and $58.9 \%$ by the sprayer. For pinkies on both vessels and the sprayer on Vessel B, between 22 and $28 \%$ of all light interactions were with the mitigation device itself (Tables $7 \& 8$ ) as opposed to the warps; however $90 \%$ of all light interactions on Vessel A were with the baffler. The observer reported that the majority of these light interactions involved the seabird's foot touching a baffler rope dragging on the sea surface.

Other than the mitigation device used, factors that most influenced heavy interactions on Vessel B were swell height, the amount of offal discharged and total retained weight of fish (Table 6). Both volume of offal discharged and swell height produced a higher rate of heavy interactions, while retention of the catch reduced heavy interactions. On Vessel A, heavy interactions were higher on the shelf as opposed to the slope, so depth category was included as a parameter in the final model.

Wind speed had no apparent effect on interaction rate on either vessel. The range of wind speeds encountered during the trials was similar across vessels and devices used, i.e.3-20 knots (kn) and 5-20 kn when using the baffler and control, respectively, on Vessel A and 0-25 $\mathrm{kn}$ and 0-20 $\mathrm{kn}$ when using the sprayer and control, respectively, on vessel B (Table 3).

More than $94 \%$ of all light and heavy interactions observed were with shy-type 
Table 5. Coefficients and significance of variables in the generalised linear model (GLM) of heavy seabird interactions on board Vessel A during a trial of the baffler in comparison with the only seabird interaction mitigation device previously prescribed, the pinkie (control). ns: non-significant at $\mathrm{p}=0.05$

\begin{tabular}{|lrrrc|}
\hline Variable & $\begin{array}{c}\text { Coeffi- } \\
\text { cient }\end{array}$ & $\begin{array}{c}\text { Residual } \\
\text { df }\end{array}$ & $\begin{array}{c}\text { Residual } \\
\text { deviance }\end{array}$ & $p$ \\
\hline Mitigation device & 2.024 & 53 & 25.269 & 0.03017 \\
Depth category & -1.409 & 52 & 23.225 & ns \\
Full model & & & 23.22 & \\
Null model & & & 29.97 & \\
\hline
\end{tabular}

Table 6. Coefficients and significance of variables in the GLM of heavy seabird interactions on board Vessel B during a trial of the sprayer in comparison with the only seabird interaction mitigation device previously prescribed, the pinkie (control). ns: non-significant at $\mathrm{p}=0.05$

\begin{tabular}{|lrccc|}
\hline Variable & $\begin{array}{c}\text { Coeffi- } \\
\text { cient }\end{array}$ & $\begin{array}{c}\text { Residual } \\
\mathrm{df}\end{array}$ & $\begin{array}{c}\text { Residual } \\
\text { deviance }\end{array}$ & $\mathrm{p}$ \\
\hline Mitigation device & -0.7853 & 67 & 84.46 & 0.010 \\
Offal discharged & 0.0064 & 66 & 81.44 & $\mathrm{~ns}$ \\
Retained weight & -0.0007 & 65 & 77.87 & $\mathrm{~ns}$ \\
Swell height & 0.6198 & 64 & 72.76 & 0.023 \\
Full model & & & 72.76 & \\
Null model & & & 91.06 & \\
\hline
\end{tabular}

albatross (Tables $7 \&$ 8). Shy-type albatross was the only species group to be observed having a heavy interaction on Vessel A, while heavy interactions with black-browed albatross and giant petrel were also observed on Vessel B. Seabird abundance observed during offal discharge was significantly correlated to both heavy (Vessel A: $r=0.28, p<0.05$; Vessel B: $r=0.36, p<0.01$ ) and light interactions (Vessel A: $r=0.55, p<0.0001$; Vessel B: $r=0.48, p<0.0001$ ). Multiple heavy interactions by Vessel $B$ were far more common when seabird abundance $\geq 300$ birds. When abundance was $>300$ birds, only 6 of the 36 shots observed resulted in no interactions.

\section{Seabird abundance}

Approximately two-thirds of the fishing effort undertaken during this project was in shelf waters less than $200 \mathrm{~m}$ depth on the continental shelf, with the remainder on the continental slope at depths to $500 \mathrm{~m}$. There was no consistent trend between depth and seabird abundance at the time of offal release
(Vessel A: r = 0.28, p > 0.05; Vessel B: $r=0.02, p>$ 0.05 ), with high and low abundances on both shelf and slope shots (Fig. 6).

Of the 14 separate species or species groups observed while trialling the baffler on board Vessel A, shy-type albatross were by far the most abundant, and were most abundant during offal discharge (average of 185.62 birds per set) and when the catch was released on deck (94.86 birds per set) (Table 7). Short-tailed shearwaters Ardenna tenuirostris were the second most abundant species seen followed by giant petrel Macronectes spp. and silver gull Larus novaehollandiae.

Fourteen different species or species groups were also observed during sprayer trials on board Vessel B (Table 8). Shy-type albatross were again by far the most commonly sighted. They were most abundant during offal discharge (263 birds per set) and as the catch was released on deck (146 birds per set). Undifferentiated petrels, prions and shearwaters (family Procellariidae), grey-headed albatross Thalassarche chrysostoma and black-browed albatross were also abundant during offal discharge.

\section{Ease and safety of use}

To facilitate alternating mitigation devices during the trial, the control and treatment devices were deployed and retrieved at the completion of each shot. Under normal fishing operations, however, the sprayer can be deployed at the beginning of a trip and left in position until the last shot of the trip. Deployment and retrieval can be undertaken at the location and time of choosing, and does not in any way interfere with the trawl gear. As such, there are clear benefits of using the sprayer over the pinkies (which need to be deployed and retrieved for each shot), being 'safer, faster, easier and more efficient' (skipper of Vessel B, pers. comm.).

During the early stages of the baffler trial, there was no simple system for retrieval and deployment, and crew members were exposed to increased risks during deployment by having to stand on the bulwarks (the extension of the hull above the deck). The system also took longer to deploy and retrieve than pinkies (about 10 min compared to $3 \mathrm{~min}$ ). However, deployment and retrieval systems were refined during the trial, eliminating the need for standing on the bulwarks, and reducing the deployment time to about 5 min. Vessel A is a 'side trawler', retrieving the codend over the side of the vessel. This means that 1 baffler needs to be retrieved during hauling for 


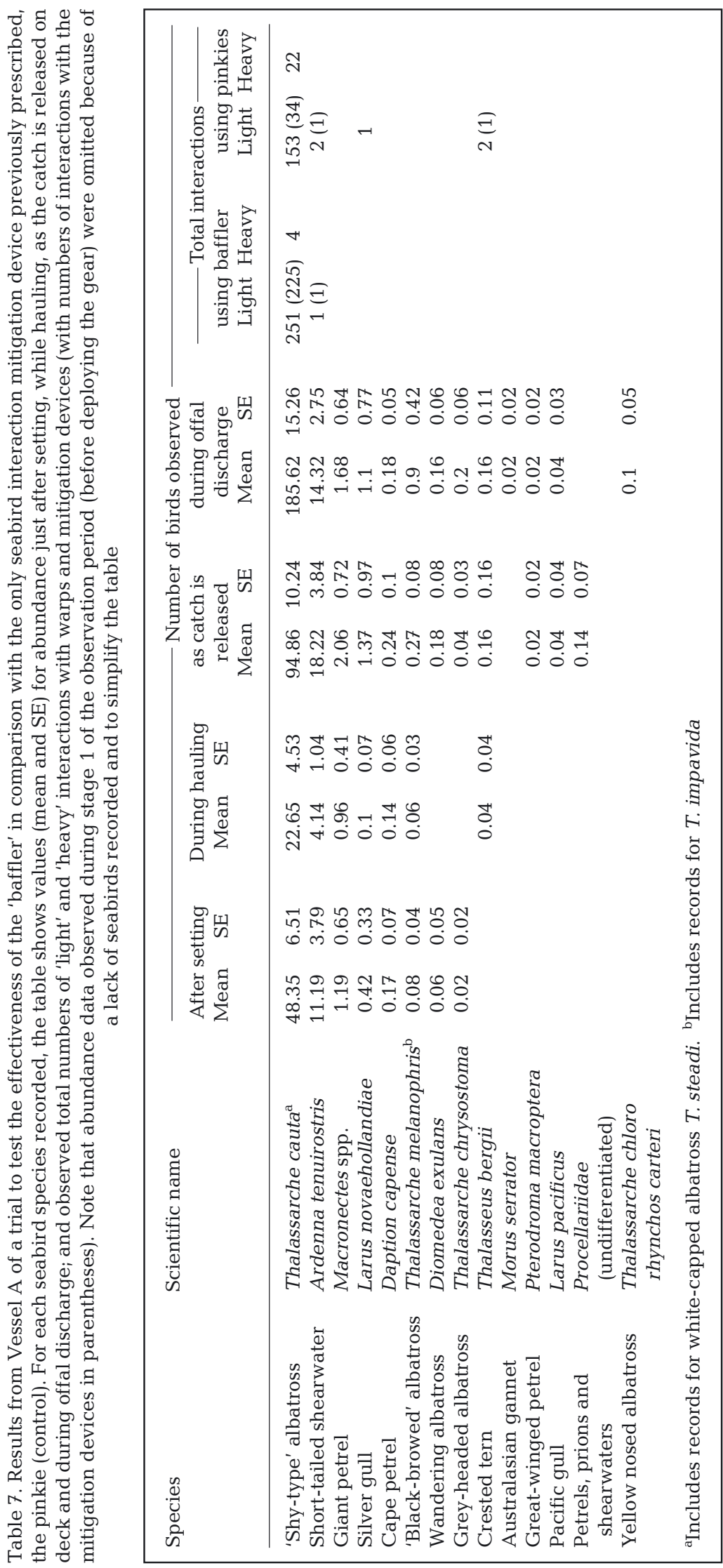

each shot. The more common vessel configuration in the fishery, i.e. the 'stern trawler', could leave both bafflers deployed while setting and retrieving the fishing gear. This has clear safety and time-saving benefits in comparison to the repeated deployment and retrieval of pinkies for each shot.

\section{DISCUSSION}

\section{Seabird mitigation}

This project demonstrated that 2 seabird mitigation devices developed from an industry-led project resulted in significant reductions in heavy interaction rates (interactions per shot) compared to the pinkie (83.7 and $58.9 \%$ for the baffler and sprinkler, respectively). These devices have now been approved by AFMA for use within the CTS and the Great Australian Bight Trawl Sector of the SESSF. As well as being easier and safer to use than the previously approved pinkies, better compliance with seabird management plans is expected because of the sense of ownership engendered by this process. As part of the transition to these new devices, SETFIA has resolved through a formal member vote that all SMPs must contain one of the following 3 mitigation devices: (1) sprayers, (2) bafflers or (3) pinkies in combination with offal management. SETFIA has strongly encouraged the use of bafflers and sprayers and uptake has been very high, reflecting the advantages of these devices in terms of reduction in seabird interactions, reduced personal risk to crew members, and the operational complexities of offal management that is required when using pinkies.

\section{Seabird interactions}

As in a previous study of mitigation devices in the CTS (Pierre et al. 2010), observed interactions overwhelmingly involved shy-type albatross. Interactions generally increased with seabird abun- 


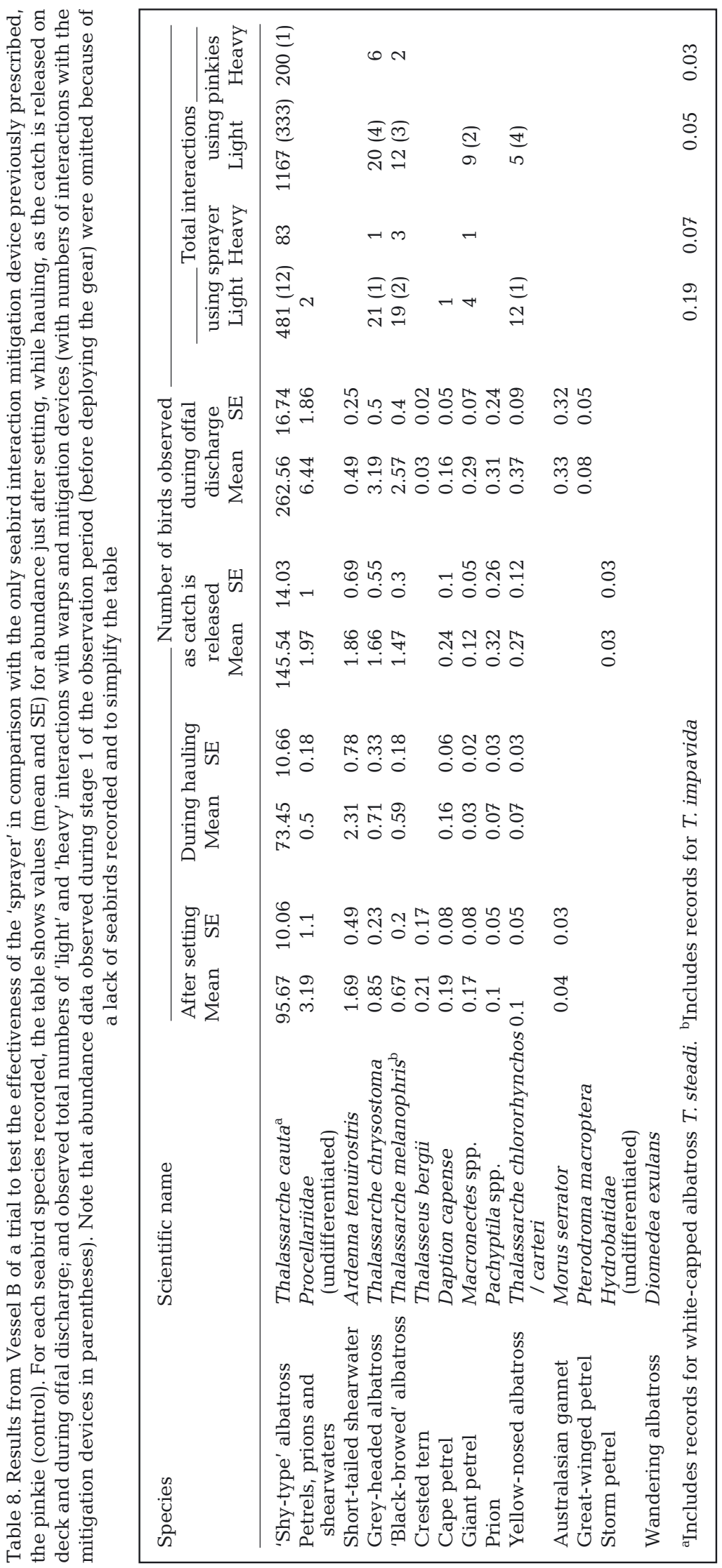

dance during offal discharge. However, the relationship does not appear to be linear, with the frequency of interactions greatly increasing when large numbers $(\geq 300)$ of seabirds were observed (Fig. 7). During the trials, it was observed that when there were large numbers of seabirds around the vessels the increased competition for food caused more aggressive, and potentially more risky, feeding behaviour.

Depth category (shelf or slope) was the only variable other than mitigation device that remained in the final model as an explanatory variable for interaction rates on board Vessel A. Little can be made of this considering that of the 9 shots in which interactions were observed on that vessel, only 2 were while fishing at depths $\geq 200 \mathrm{~m}$, but it is consistent with the known behaviour of shy albatross, which have an overwhelming tendency to restrict their foraging to shelf waters (e.g. Hedd et al. 2001, Alderman et al. 2010). However, while fishing depths reported during this study ranged between 55 and $510 \mathrm{~m}$, observations during this study found no influence of fishing depth on seabird abundance.

There were 3 variables other than mitigation device that had an influence on interaction rates on board Vessel B using the sprayer, namely, the volume of offal discharge, catch weights and swell height:

1. The volume of offal discharge was retained in the final model by the AIC: the greater the volume of offal discharged the greater the number of heavy interactions. The main effect of increased offal discharge is likely due to the prolonged discharging period, which increases the danger period for warp strikes.

2. In general, there were fewer heavy interactions at higher retained catch weights. This is the opposite response from what was expected because larger catches take a longer time to haul and sort the catch, and in general, there is a positive relationship between retained catches and both discards and offal (unpubl. data). This result can probably be explained by the influence of several very large $(>2 \mathrm{t})$ catches for which there were few heavy interactions. 


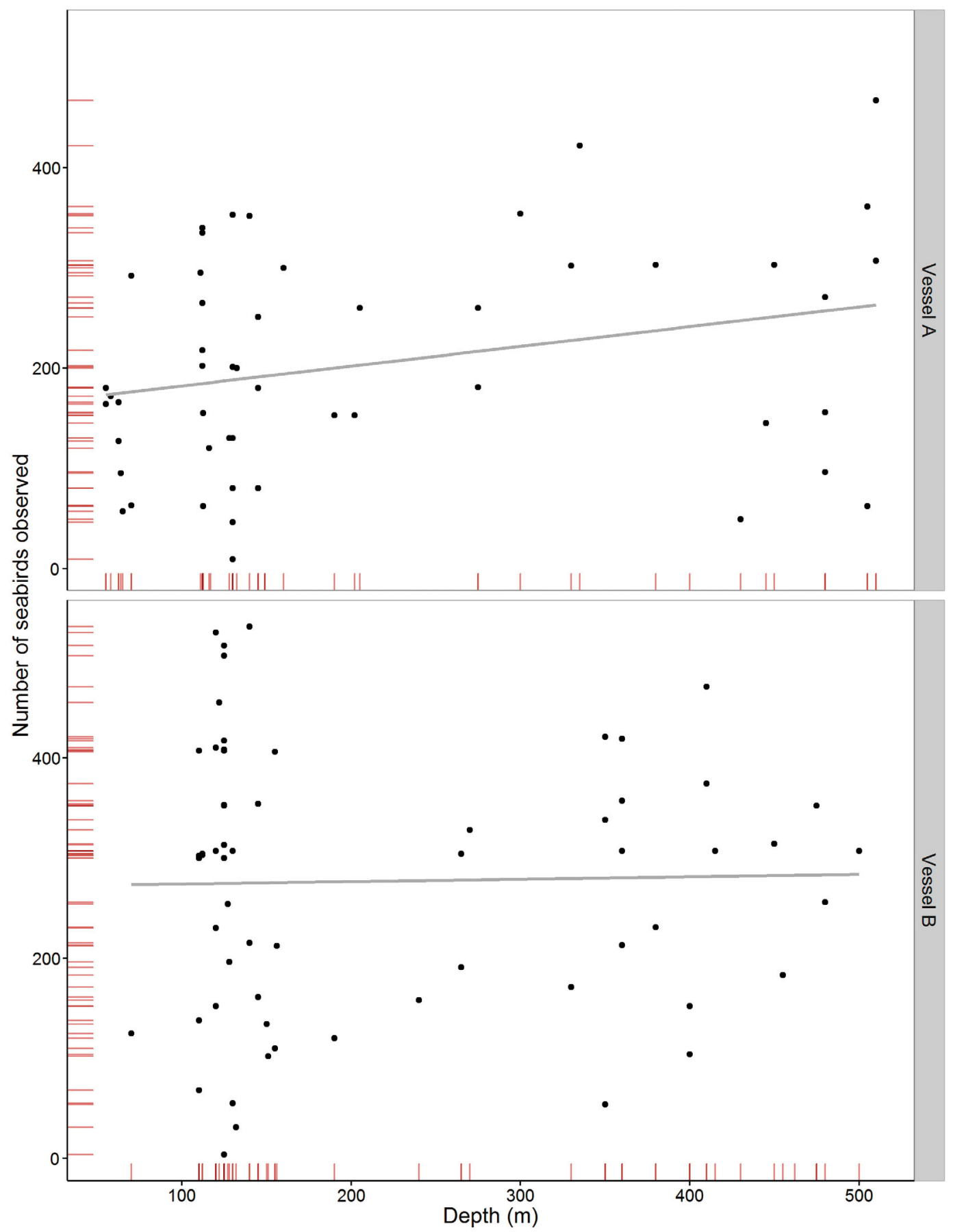

Fig. 6. Number of seabirds observed at offal discharge by depth $(\mathrm{m})$ for each vessel during trials of 2 experimental seabird interaction mitigation devices, the baffler (fitted on Vessel A) and water sprayer (Vessel B). Rug lines indicate observations along the $x$ - and $y$-axis. Lines are smoothed conditional means

3. Swell height had a significant positive effect on heavy interactions (Table 6), and this effect was similar across treatments. The warps rise and fall quickly through the sea surface during large swell, effectively increasing the size of the danger zone, and possibly reducing the seabirds' ability to detect and avoid the warp. These observations are consistent with Sullivan et al. (2006a) and Melvin et al. (2011), who also noted increases in interactions with increased swell height. 


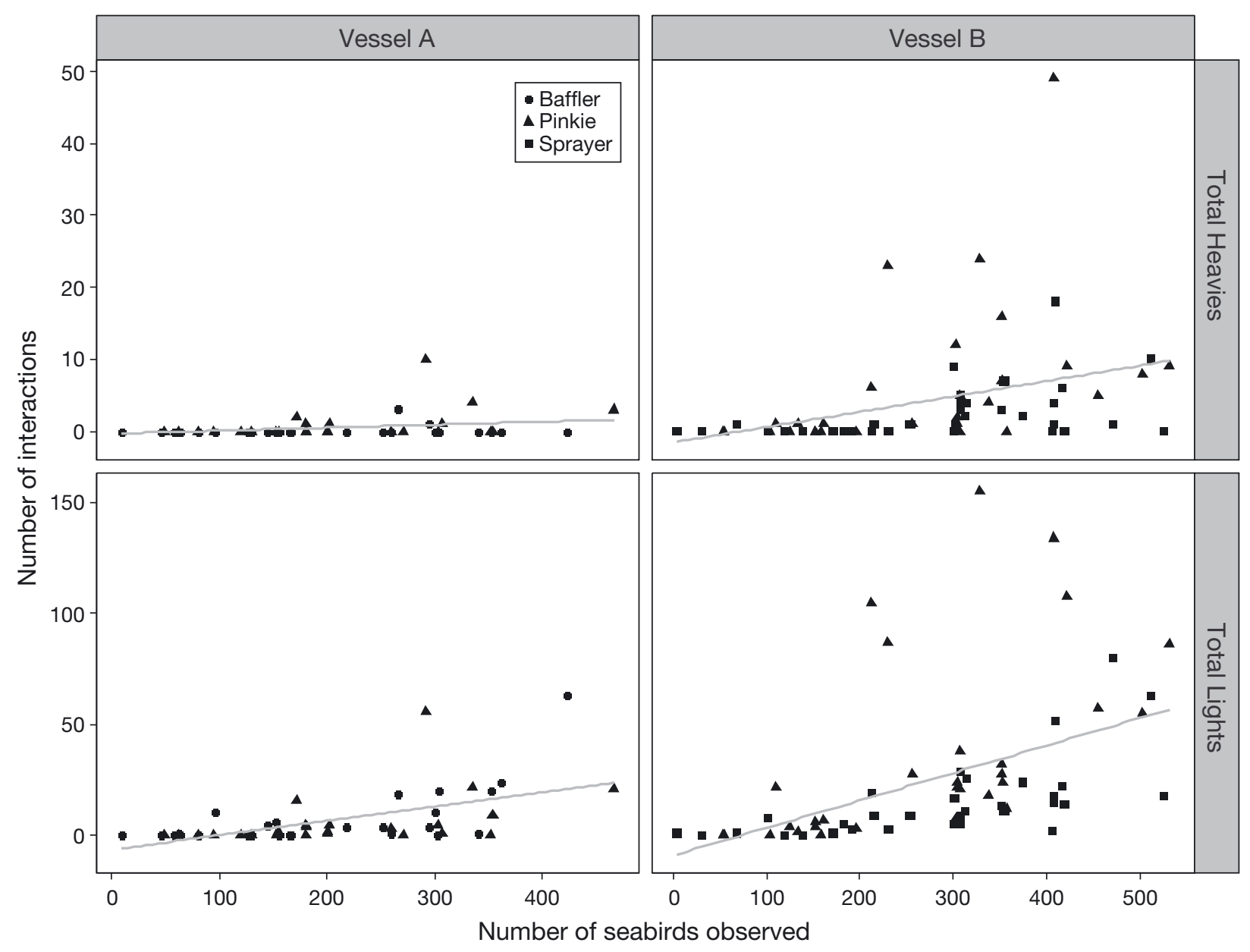

Fig. 7. Influence of the number of seabirds observed on the number of heavy and light interactions during trials of the baffler (fitted on Vessel A, left panels) and water sprayer (Vessel B, right panels) in comparison with the only seabird interaction mitigation device previously prescribed, the pinkie (control). Lines are smoothed conditional means

Because deceased seabirds rarely remain attached to the warps during hauling, it was not possible to directly measure seabird mortalities in this study. Sullivan et al. (2006a) found a positive relationship between heavy interactions and mortalities in a demersal trawl fishery in the Falkland Islands (Las Malvinas), and this is often used as a proxy measurement for mortalities (e.g. Melvin et al. 2011, Maree et al. 2014). In this study there was no information available on the relation between heavy interactions and mortalities, however we assume that it was consistent among treatments.

\section{The baffler}

On Vessel A, heavy interactions were significantly lower while using the baffler compared to the pinkie (the control device) (Fig. 5, Table 5). While a previous study found that pinkies reduced heavy interactions by about $75 \%$ compared to using no mitigation device at all (Pierre et al. 2010), we found that the baffler was $83.7 \%$ more effective than the pinkies in reducing heavy interactions. Because pinkies were used as the control in this trial, and bafflers reduced interactions by a further $83.7 \%$, this potentially represents an overall decrease in heavy interactions of $96 \%$ compared to using no mitigation device at all. The rate of light interactions was higher for the baffler than pinkies; however, the vast majority of light interactions were with the flexible droppers or the back-bone of the baffler itself, rather than with the warps, and thus were unlikely to cause harm to the seabirds involved. The baffler is simple and safe to deploy, and no major maintenance issues were reported during the study. 


\section{The water sprayer}

Trials revealed that the use of the water sprayer on Vessel B significantly reduced seabird interactions compared with using the pinkie (Fig. 5, Table 6). The water sprayer was $58.9 \%$ more effective at reducing interactions than the pinkies. Because pinkies have been shown to reduce heavy interactions by $75 \%$, and sprayers reduced interactions in our trials by a further $58.9 \%$, with the reduced interaction rate from using the pinkies, this potentially represents an overall decrease in heavy interactions of $90 \%$ compared to using no mitigation device at all. The water sprayer also has the additional advantages that it can be set at the beginning of the trip and left on until the end of the trip, and the crew can decide under what conditions they deploy and retrieve it (e.g. while leaving port). In this trial, there were no discernible safety issues with the device. The water sprayer required some ongoing maintenance during the trial; specifically, the boom and nozzle position sometimes required adjustment, depending on wind direction, to ensure an adequate coverage of water. However the pinkies also required maintenance, including untangling and replacing rope and lost buoys.

\section{Impacts on seabird populations}

By far the most common species observed and involved in interactions was the shy-type albatross (Tables $7 \& 8$ ). The distribution of shy albatross overlaps with that of white-capped albatross, and the 2 species are phenotypically similar (Baker et al. 2007). Thomson \& Sagar (2008) presented tracking data from white-capped albatross that showed movement between New Zealand and southeast Australia, including the area fished during mitigation trials. Further, Baker et al. (2007) estimated that the number of white-capped albatross killed each year was higher than shy albatross. The composition of each species observed in the shy-type albatross grouping is unknown, but it is likely that both were present.

Shy albatross are listed as vulnerable under the Environment Protection and Biodiversity Conservation Act which came into force in 1999. They are endemic to Australia, with a population estimated to total 55000 to 60000 individuals (Alderman et al. 2011), or 12200 breeding pairs. Breeding colonies are restricted to 3 islands off Tasmania: Albatross Island, the Mewstone and Pedra Branca (Alderman et al. 2011). In addition, the foraging distribution of the shy albatross is concentrated in Australian waters (Alderman et al. 2010,
2011). Given the endemism, high local abundance and extensive spatial and temporal overlap with fishing effort, combined with their large size and foraging behaviour, this species has one of the highest likelihoods of interacting with southern Australian fisheries; trawl and longline interactions for this species have been documented from Australia, South Africa, Namibia, and the high seas (Baker et al. 2007 and references therein). Although documented bycatch of shy albatross in Australian commercial fisheries is low, it is in practice likely much higher due to the cryptic nature of interactions where deceased birds are not returned to the vessel when the trawl net is retrieved.

Offal management has alone been shown to be effective in reducing seabird interactions (for example, Abraham et al. 2009, Bull 2009, Pierre et al. 2012a,b), and the use of the pinkie has been shown to be effective in the CTS (Pierre et al. 2014). Results of the current study show that compared to the pinkie, the sprayer and baffler reduced heavy interactions by $58.9 \%$ and $83.7 \%$ respectively, resulting in a potential reduction in seabird interactions of $90 \%$ and $96 \%$ compared to no mitigation device. Given the uptake of the bafflers and the sprayer in the CTS (about 95\% of active vessels in total), it is likely the fishery has reduced bycatch beyond the predicted 50\% (from 2010 levels) needed to offset losses due to potential future temperature changes (Thomson et al. 2015).

\section{Management implications}

This industry-led project directly addressed the Australian Government policy of 'bycatch reduction, improved protection for protected species and minimising any adverse impacts of bycatch on the marine environment' (AFMA 2008), and supports the SESSF's 2016 Wildlife Trade Operation certification scheme which includes the requirement to implement management measures including bycatch devices to address the risk of seabird interactions. The study has also resulted in the design, construction and implementation of 2 seabird mitigation devices that perform significantly better than the previously prescribed device. Engagement with AFMA was critical to this project's success and was facilitated by AFMA representation on the project's steering committee. AFMA was involved throughout the project, including in the experimental design, provision of scientific permits for trials, description of requirements for a new device to be approved for use in seabird management plans and in the application to have devices approved. 
This research has demonstrated that mitigation devices can be highly effective in removing heavy interactions. The 2 devices trialled by this project have shown significant potential to further reduce seabird interactions.

Results of this project have directly influenced management arrangements by providing flexibility to fishers in fulfilling the requirements of SMPs. While this project clearly demonstrated that the trial devices exceeded performance of the control in reducing seabird interactions, we acknowledge that this study was limited to the 2 vessels used, and in the area of the fishery covered. Pinkies have been shown to effectively reduce seabird interactions (Pierre et al. 2014), and retention of them as an approved device (with the addition of offal management) as a permitted seabird mitigation device maintains flexibility for vessels operating infrequently. Based on results of this study, however, SETFIA has strongly encouraged its members to use bafflers and, as of December 2017, of the 37 active demersal trawl vessels in the CTS, 1 vessel is using sprayers, 2 part-time vessels are using pinkies/offal management and the remainder of the fleet are using bafflers.

This study shows that positive environmental outcomes can be achieved when industry members take ownership of their conservation challenges. Our study suggests that both sprayers and bafflers can provide substantial improvements to the conservation status of seabirds, in addition to the health and safety of crew, and should be considered for implementation in other trawl fisheries in Australia and globally.

Acknowledgements. We thank the anonymous owners, skippers and crew of fishing Vessel A (baffler) and Vessel B (sprayer) for participating in this project. In particular, we would like to thank Sot Sotirakis (J\&S Welding and a CTS operator), Tony Guarnaccia, Trevor Hunt for design and construction of the sprayer, as well as Josh Jarvis, John Jarvis, Fritz Drenkhahn, Lucas Holley (Nobby) and Steve Buckless for design, trial logistics and construction of the baffler. This project was supported by SETFIA, through funding by a National Landcare Programme Innovation Grant from the Australian Government. This project was overseen by a steering committee comprised of Brad Warren (OceanWatch), Cameron Dixon (formally WWF), Russell Glover (formerly NRM), Tony Guarnaccia (CTS Industry member), Jonathon Barrington (AAD), and Mike Gerner (AFMA). The scientific observers were Russel Hudson, Andrew Trappett and Kade Mills. Robin Thomson (CSIRO) made valuable comments on the draft of this paper. Bill Venables (CSIRO) is thanked for providing advice on use of the glm.nb function. We thank 2 anonymous referees for their comments which greatly improved this manuscript. Lastly this project only occurred because fishing industry members (through SETFIA and GABIA) saw a strategic and ethical need to complete this work.

\section{LITERATURE CITED}

Abraham ER (2010) Warp strike in New Zealand trawl fisheries 2004-05 to 2008-09. New Zealand Aquatic Environment and Biodiversity Report 60, Ministry of Fisheries, Wellington

Abraham ER, Pierre JP, Middleton DAJ, Cleal J, Walker NA, Waugh SM (2009) Effectiveness of fish waste management strategies in reducing seabird attendance at a trawl vessel. Fish Res 95:210-219

ACAP (Agreement on the Conservation of Albatrosses and Petrels) (2016) ACAP summary advice for reducing impact of pelagic and demersal trawl gear on seabirds. Agreement on the Conservation of Albatrosses and Petrels. Reviewed at the Ninth Meeting of the Advisory Committee, La Serena, Chile, 9-13 May 2016. https:// www.acap.aq/en/resources/bycatch-mitigation/mitigationadvice/202-acap-review-of-mitigation-measures-andsummary-advice-for-reducing-the-impact-of-pelagicand-demersal-trawl-gear-on-seabirds/file (accessed 8 July 2018)

AFMA (Australian Fisheries Management Authority) (2008) AFMA's Program for Addressing Bycatch and Discarding in Commonwealth Fisheries: an implementation strategy, March 2008.Australian Fisheries Management Authority, Canberra. www.afma.gov.au/wp-content/uploads/ 2014/11/Bycatch-and-Discarding-ImplementationStrategy-feb-08.pdf (accessed 28 June 2016)

Alderman R, Gales R, Hobday A, Candy S (2010) Post-fledging survival and dispersal of shy albatrosses from three breeding colonies in Tasmania. Mar Ecol Prog Ser 405: 271-285

Alderman R, Gales R, Tuck GN, Lebreton JD (2011) Global population status of shy albatross and an assessment of colony-specific trends and drivers. Wildl Res 38:672-686

ANAO (Australian National Audit Office) (2013) Administration of the Domestic Fishing Compliance Program: Australian Fisheries Management Authority. Audit Report 20, Australian National Audit Office, Barton. https://www. anao.gov.au/work/performance-audit/administrationdomestic-fishing-compliance-program

Baker GB, Double MC, Gales R, Tuck GN and others (2007) A global assessment of the impact of fisheries-related mortality on shy and white-capped albatrosses: conservation implications. Biol Conserv 137:319-333

* Boyd C (2014) Minimizing seabird bycatch in industrial fisheries. Anim Conserv 17:530-531

* Brothers N (1991) Albatross mortality and associated bait loss in the Japanese longline fishery in the Southern Ocean. Biol Conserv 55:255-268

Bull LS (2009) New mitigation measures reducing seabird bycatch in trawl fisheries. Fish Fish 10:408-427

Canty A, Ripley B (2014) boot: bootstrap R (S-plus) functions. $\mathrm{R}$ package version 1.3-11. https://cran.r-project.org/ package $=$ boot

Crawford RJM (2007) Food, fishing and seabirds in the Benguela upwelling system. J Ornithol 148(Suppl 2): 253-260

* Croxall JP, Butchart SHM, Lascelles B, Stattersfield AJ, Sullivan BJ, Symes A, Taylor P (2012) Seabird conservation status, threats and priority actions: a global assessment. Bird Conserv Int 22:1-34

DSEWPC (Department of Sustainability Environment, Water, Population and Communities) (2011) National recovery plan for threatened albatrosses and giant petrels 
2011-2016, Commonwealth of Australia, Hobart www. environment.gov.au/resource/national-recovery-planthreatened-albatrosses-and-giant-petrels-2011\%E2\%80 \%942016 (accessed 20 July 2016)

Favero M, Seco Pon JP (2014) Challenges in seabird bycatch mitigation. Anim Conserv 17:532-533

Favero M, Blanco G, García G, Copello S and others (2011) Seabird mortality associated with ice trawlers in the Patagonian shelf: effect of discards on the occurrence of interactions with fishing gear. Anim Conserv 14:131-139

Gales R (1998) Albatross populations: status and threats. In: Robertson G, Gales R (eds) Albatross: biology and conservation. Surrey Beatty \& Sons, Chipping Norton, p 20-45

González-Zevallos D, Yorio P, Caille G (2007) Seabird mortality at trawler warp cables and a proposed mitigation measure: a case of study in Golfo San Jorge, Patagonia, Argentina. Biol Conserv 136:108-116

González-Zevallos D, Yorio P, Svagelj WS (2011) Seabird attendance and incidental mortality at shrimp fisheries in Golfo San Jorge, Argentina. Mar Ecol Prog Ser 432: 125-135

Hedd A, Gales R, Brothers N (2001) Foraging strategies of shy albatross Thalassarche cauta breeding at Albatross Island, Tasmania, Australia. Mar Ecol Prog Ser 224: 267-282

Lewison RL, Crowder LB, Wallace BP, Moore JE and others (2014) Global patterns of marine mammal, seabird, and sea turtle bycatch reveal taxa-specific and cumulative megafauna hotspots. Proc Natl Acad Sci USA 111: 5271-5276

Maree BA, Wanless RM, Fairweather TP, Sullivan BJ, Yates O (2014) Significant reductions in mortality of threatened seabirds in a South African trawl fishery. Anim Conserv 17:520-529

Melvin EF, Dietrich KS, Fitzgerald S, Cardoso T (2011) Reducing seabird strikes with trawl cables in the pollock catcher-processor fleet in the eastern Bering Sea. Polar Biol 34:215-226

Moore JE, Zydelis R (2008) Quantifying seabird bycatch: Where do we go from here? Anim Conserv 11:257-259

Nel DC, Ryan P, Watkins BP (2002) Seabird mortality in the Patagonian toothfish longline fishery around the Prince Edward Islands, 1996-2000. Antarct Sci 14:151-161

Phillips K, Giannini F, Lawrence E, Bensley N (2010) Cumulative assessment of the catch of non-target species in Commonwealth fisheries: a scoping study. Bureau of Rural Sciences, Canberra

Pierre JP, Abraham ER, Middleton DAJ, Cleal J, Bird R, Walker NA, Waugh SM (2010) Reducing interactions between seabirds and trawl fisheries: responses to foraging patches provided by fish waste batches. Biol Conserv 143:2779-2788

Pierre JP, Abraham ER, Richard Y, Cleal J, Middleton DAJ (2012a) Controlling trawler waste discharge to reduce seabird mortality. Fish Res 131-133:30-38

Pierre JP, Abraham ER, Cleal J, Middleton DAJ (2012b) Reducing effects of trawl fishing on seabirds by limiting foraging opportunities provided by fishery waste. Emu 112:244-254

Pierre JP, Gerner M, Penros L (2014) Assessing the effectiveness of seabird mitigation devices in the trawl sectors of the Southern and Eastern Scalefish and Shark Fishery in Australia. Final Report. Australian Fisheries Management Authority, Canberra

R Development Core Team (2014) R: a language and environment for statistical computing. R Foundation for Statistical Computing, Vienna

Ramm K (2012) Conservation Services Programme observer report, 1 July 2009 to 30 June 2010. Final Report, Department of Conservation, Wellington

Sullivan BJ, Brickle P, Reid TA, Bone DG, Middleton DAJ (2006a) Mitigation of seabird mortality on factory trawlers: trials of 3 devices to reduce warp cable strikes. Polar Biol 29:745-753

Sullivan BJ, Reid TA, Bugoni L (2006b) Seabird mortality on factory trawlers in the Falkland Islands and beyond. Biol Conserv 131:495-504

Thomson D, Sagar P (2008) A population and distributional study of white-capped albatross (Auckland Islands). Contract number: POP 2005/02. Report prepared for the Conservation Services Programme, Department of Conservation, Wellington, July 2008. www.doc.govt.nz/documents/ conservation/marine-and-coastal/fishing/pop2005-02white-capped-albatross-ar-07-08.pdf (accessed 15 June 2016)

* Thomson RB, Alderman RL, Tuck GN, Hobday AJ (2015) Effects of Climate change and fisheries bycatch on shy albatross (Thalassarche cauta) in southern Australia. PLOS ONE 10:e0127006

Tuck GN, Polacheck T, Bulman CM (2003) Spatio-temporal trends of longline fishing effort in the Southern Ocean and implications for seabird bycatch. Biol Conserv 114: $1-27$

Tuck GN, Phillips RA, Small C, Thomson RB, Klaer NL and others (2011) An assessment of seabird-fishery interactions in the Atlantic Ocean. ICES J Mar Sci 68:1628-1637

Tuck GN, Knuckey I, Klaer NL (2013) Informing the review of the Commonwealth Policy on Fisheries Bycatch through assessing trends in bycatch of key Commonwealth fisheries. Final report 2012/046, Fisheries Research and Development Corporation, Canberra

Venables WN, Ripley BD (2002) Modern applied statistics with S, 4th edn. Springer, New York, NY

*Wanless RM, Maree BA (2014) Problems and solutions for seabird bycatch in trawl fisheries. Anim Conserv 17:534

Warham J (1990) The petrels: their ecology and breeding systems. Academic Press, New York, NY

Watkins BP, Petersen SL, Ryan PG (2008) Interactions between seabirds and deep water hake trawl gear: an assessment of impacts in South African waters. Anim Conserv 11:247-254

Weimerskirch H, Brothers N, Jouventin P (1997) Population dynamics of wandering albatross Diomedea exulans and Amsterdam albatross D. amsterdamensis in the Indian Ocean and their relationships with long-line fisheries: conservation implications. Biol Conserv 79:257-270

*Weimerskirch H, Capdeville D, Duhamel G (2000) Factors affecting the number and mortality of seabirds attending trawlers and long-liners in the Kerguelen area. Polar Biol 23:236-249

Williams R, Capdeville D (1996) Seabird interactions with trawl and longline fisheries for Dissostichus eleginoides and Champsocephalus gunnari. CCAMLR Sci 3:93-99 